\title{
Characterization of Black Spot Zones for Vulnerable Road Users in São Paulo (Brazil) and Rome (Italy)
}

Cláudia A. Soares Machado ${ }^{1, *}$, Mariana Abrantes Giannotti ${ }^{1}$, Francisco Chiaravalloti Neto ${ }^{2}$, Antonino Tripodi ${ }^{3}$, Luca Persia ${ }^{3}$ and José Alberto Quintanilha ${ }^{1}$

1 Laboratory of Geoprocessing, Department of Transportation Engineering, Polytechnic School of the University of São Paulo, Av. Prof. Almeida Prado, Travessa 2, 83, SP 05508-070 São Paulo, Brazil; E-Mails: mariana.giannotti@gmail.com (M.A.G.); jaquinta@usp.br (J.A.Q.)

Department of Epidemiology, School of Public Health of the University of São Paulo, Av. Dr. Arnaldo, 715, SP 01246-904 São Paulo, Brazil; E-Mail: franciscochiara@usp.br

3 Centro di Ricerca per il Trasporto e la Logistica, Università di Roma, Piazzale Aldo Moro, 5, Roma 00185, Italy; E-Mails: tripodi@ctl.uniroma1.it (A.T.); luca.persia@uniroma1.it (L.P.)

* Author to whom correspondence should be addressed; E-Mail: csmachado6@gmail.com; Tel.: +55-11-3091-5173 or $+55-11-3091-5504$.

Academic Editors: Mark Zuidgeest and Wolfgang Kainz

Received: 30 October 2014 / Accepted: 8 May 2015 / Published: 20 May 2015

\begin{abstract}
Non-motorized transportation modes, especially cycling and walking, offer numerous benefits, including improvements in the livability of cities, healthy physical activity, efficient urban transportation systems, less traffic congestion, less noise pollution, clean air, less impact on climate change and decreases in the incidence of diseases related to vehicular emissions. Considering the substantial number of short-distance trips, the time consumed in traffic jams, the higher costs for parking vehicles and restrictions in central business districts, many commuters have found that non-motorized modes of transportation serve as viable and economical transport alternatives. Thus, local governments should encourage and stimulate non-motorized modes of transportation. In return, governments must provide safe conditions for these forms of transportation, and motorized vehicle users must respect and coexist with pedestrians and cyclists, which are the most vulnerable users of the transportation system. Although current trends in sustainable transport aim to encourage and stimulate non-motorized modes of transportation that are socially more efficient than motorized transportation, few to no safety policies have been implemented regarding vulnerable road users (VRU), mainly in large urban centers. Due to the spatial nature of the data used in transport-related studies,
\end{abstract}


geospatial technologies provide a powerful analytical method for studying VRU safety frameworks through the use of spatial analysis. In this article, spatial analysis is used to determine the locations of regions that are characterized by a concentration of traffic accidents (black zones) involving VRU (injuries and casualties) in São Paulo, Brazil (developing country), and Rome, Italy (developed country). The black zones are investigated to obtain spatial patterns that can cause multiple accidents. A method based on kernel density estimation (KDE) is used to compare the two cities and show economic, social, cultural, demographic and geographic differences and/or similarities and how these factors are linked to the locations of VRU traffic accidents. Multivariate regression analyses (ordinary least squares (OLS) models and spatial regression models) are performed to investigate spatial correlations, to understand the dynamics of VRU road accidents in São Paulo and Rome and to detect factors (variables) that contribute to the occurrences of these events, such as the presence of trip generator hubs (TGH), the number of generated urban trips and demographic data. The adopted methodology presents satisfactory results for identifying and delimiting black spots and establishing a link between VRU traffic accident rates and TGH (hospitals, universities and retail shopping centers) and demographic and transport-related data.

Keywords: spatial analysis; kernel density estimator; vulnerable road users; traffic accidents; trip generator hubs

\section{Introduction}

One key element of modern transportation systems is safety. The goal of safety is to minimize the number of accidents and to reduce the severity of injuries for all users, including motorists, passengers of particular vehicles, public transport commuters, cyclist and pedestrians [1,2].

Traffic accidents result in the second highest cost of transportation. These costs result from personal damage (injuries and wounds), fatalities, property damage (to vehicles and other public or private property), degradation of quality of life and decreases in available time for conducting activities and maintaining social relationships [3-5].

Non-motorized modes of transportation, especially cycling and walking, offer numerous benefits, including improvements in the livability of cities, healthy physical activity, an efficient urban transportation system, less traffic congestion, less noise pollution, clean air, less impact on climate change, decreased incidence of diseases related to vehicular emissions, decreased fossil fuel use and decreased transportation costs. Considering the substantial number of short-distance trips, the time consumed in traffic jams, higher vehicle parking costs and restrictions in central business districts, many commuters have found that non-motorized modes of transportation are viable and economical transportation alternatives [6].

Thus, non-motorized modes of transportation should be stimulated and encouraged by local governments. In return, governments must provide safe conditions for these users and the users of motorized transport that allow motorized transportation to exist in harmony with pedestrians and cyclists. Planners and 
engineers must accommodate the needs of cyclists and pedestrians by designing transportation facilities for urban areas [7].

It is widely recognized that pedestrians and cyclists are the most vulnerable users of the transportation system. Although current trends in sustainable transport aim to encourage and stimulate non-motorized modes of transportation that are socially more efficient than motorized modes, few to no safety policies related to vulnerable road users (VRU) (traffic participants without outer protective cells) [8] have been implemented in large urban centers. Therefore, it is important to promote a conceptual road safety framework to reduce and control accident risks involving VRU. The risks (crash risk and injury severity) result from travel behavior (volume, modal split and distribution of traffic over time and space) and the characteristics of the transport infrastructure, such as the type of vehicle and road user [9].

The road safety framework for VRU is affected by land use and urban infrastructure (built environment). This framework is an abstraction or simplification of reality that can be used to help planners, policy makers and decision makers better understand real-world systems, facilitate communication and integrate knowledge across a variety of engineering and scientific disciplines, including transportation science, geography, urban planning, economics and physics $[9,10]$.

Due to the spatial nature of the data involved in transport-related studies, geospatial technologies provide a powerful analytical method for studying VRU safety frameworks through the use of spatial analysis. The rapid development of geographic information science and its related technologies has resulted in the collection of ample transportation data to better understand road traffic accident patterns and the behaviors of transportation system users [10]. In addition, the availability of real-time traffic data obtained through geospatial technologies increased and proactively stimulated proactive safety management in transport networks [11]. In contrast with conventional approaches, geospatial methods are used to analyze the spatial patterns of accident locations within a network space and are not affected by the configuration of the street network or its distance [12]. During the last few years, the identification of hazardous locations, which are called black spot zones, in road networks has substantially progressed. The identification of black spot zones is facilitated by the application of geospatial technologies in transportation research, which has enabled precise localization of traffic accidents and the identification of spatial patterns involving regions with a high occurrence of traffic accidents [13].

The objective of this study is to determine the locations of the regions (that contain the critical road sections) that are characterized by a concentration of traffic accidents (black zones) involving VRU (injuries and casualties) in São Paulo, Brazil (emerging country), and Rome, Italy (developed country). The black zones are investigated to obtain spatial patterns that result in multiple accidents. A method based on kernel density estimation (KDE) is applied to analyze economic, social, cultural, demographic and geographic patterns of urban road accidents in São Paulo and Rome and to investigate how these factors are linked to the locations of VRU traffic accidents. Moreover, to understand the spatial interactions that occur between VRU traffic accidents and their locations, multivariate regression analyses (Ordinary Least Squares (OLS) models and spatial regression models) are performed. In addition, these analyses are performed to determine the most important attributes that contribute to the high rates of VRU traffic accidents in a given region. 


\section{Background}

This literature review mainly discusses three aspects related to the spatial characterization of hot spots involving VRU, traffic accident research, accidents involving VRU and the spatial analysis of these accidents.

\subsection{Traffic Accident Research}

One of the most troubling problems of transportation systems is related to accidents. Road traffic accidents result in serious societal problems with significant individual, property and society costs $[2,14]$. The World Health Organization (WHO) indicates that road traffic injuries comprise a major, but neglected global public health problem that requires action for effective and sustainable prevention [15]. According to the WHO, 1.24 million people were killed worldwide in 2010 due to traffic accidents. Middle-income countries, which are becoming motorized rapidly, are the hardest hit by traffic accidents, with approximately $70 \%$ of traffic-related deaths occurring in these countries [16,17]. This tragic scenario indicates that traffic accidents are a serious public health and welfare concern and can be considered as a global epidemic [12]. The cost of dealing with the consequences of these traffic accidents reaches billions of dollars [17], which is a large sum that could be used in the transportation system to prevent traffic accidents. Half of all road traffic deaths involve VRU [17]. In Brazil, 4\% of the individuals that died from traffic accidents were cyclists and 23\% were pedestrians in 2010 [18].

Land use environments influence the needs and behaviors of VRU. The choice of a transport mode (non-motorized or motorized) varies with the land use type. For example, the number of parked bicycles at transit stations, the percentages of land for commercial use, the distances between origins and destinations and the nearest bus stop with services serving the transit station affect transport mode decisions. These factors are influential when promoting non-motorized transport. Moreover, the most significant concern regarding non-motorized transportation is the risk of traffic accidents. The accident risk varies with the level and type of local traffic. Traffic accident risk is the most important concern for VRU in urban centers [19].

In recent years, an increasing number of research studies have been conducted regarding traffic accident patterns through spatial approaches. An approach (similar to that developed in this study) was conducted by [20] that identified and delimited road sections that were characterized by concentrations of traffic accidents (black zones) by applying and comparing two methods, local spatial autocorrelation indices (a decomposition of the Global Moran Index) and KDE, without any reference to the spatial patterns of the accidents. In the study presented by [21] was used a Geographic Information System (GIS) and log-linear model to investigate the spatial distribution of pedestrian/cyclist accidents involving school-aged children in Florida, USA, and examined the conditions under which these events were more likely to occur. In the research performed by [13] was developed a procedure for identifying and evaluating clusters (black spot zones) of traffic accidents by using the KDE in the Southern Moravia Region of the Czech Republic. A spatial and temporal analysis of VRU traffic accidents in Santiago, Chile, was conducted by [22], in order to identify the most critical areas (black spot zones) in a GIS environment (using the KDE and Moran Index), and also to detect the attributes and the contributing factors (for example, time of day, straight road sections and intersections and roads without traffic signs 
within the critical areas) associated with VRU traffic accidents. The relationships between three years of pedestrian crash counts across census tracts in Austin, Texas (United States), and several land use networks and demographic attributes, such as land use balance, residents' access to commercial land uses, sidewalk density, lane-mile densities (by roadway class) and population and employment densities (by type) were examined by [23]. A study was presented by [24], which integrated a spatial density analysis (KDE) and the local Moran Index to detect black spot zones of traffic accidents and to formally evaluate the extensiveness of locations with high densities to provide tools and information for planners and decision makers to effectively allocate resources for accident prevention and safety improvement. A spatial-temporal analysis of road accidents in New Brunswick, Canada, to study the impacts of climate change on hazardous weather-related traffic accidents was provided by [25]. In addition, a spatial analysis (KDE and wavelet analysis) to identify black spot regions of traffic accidents and to verify patterns that contributed to accidents that occurred in the black spot zones in Paraná State, Brazil, was applied by [26]. A spatiotemporal analysis of intra-urban traffic accidents in metropolitan Shiraz, Iran, was presented by [27], whose objective was to identify accident-prone zones and sensitive hours using GIS-based spatio-temporal visualization techniques. This analysis is aimed at identifying high-rate accident locations and safety deficient areas by using the KED method. A spatial Bayesian modeling approach was proposed by [28] to predict VRU accident risks for a road network and to identify how road infrastructures influence VRU safety in Brussels, Belgium. An approach was introduced by [29] for the identification of hazardous accident zones that compares spatial and non-spatial methods. Overall, the study concludes that spatial analysis methods outperform non-spatial approaches, because they do not require the segmentation of highways. The only information that is required when using the spatial analysis method to identify black spot zones is the location of each accident.

\subsection{VRU Traffic Accidents}

In developing countries, accidents involving VRU constitute a much larger fraction of all traffic-related fatalities and injuries than those in developed countries. Studies and observations have indicated that a large fraction of VRU injuries and fatalities occur at urban intersections (approximately one-third) and in collisions with automobiles (about two-thirds). Most VRU accidents are caused by a combination of behavioral, technological and environmental factors, which indicates that the safety of VRU should be improved. In developing countries, safety can be improved by adopting safety principles that have reduced the number of injuries and casualties in VRU traffic accidents in developed countries, such as adequate road design and traffic management [30,31].

The characteristics of mixed traffic, the inadequate driving abilities of vehicle drivers, the behavior of users of the transportation system (the drivers of motorized and non-motorized vehicles, passengers and pedestrians), vehicle factors (such as insufficient maintenance), poor design and layout of roads and other transport infrastructure and weather conditions frequently render traffic in a country unsafe and can influence the occurrence of accidents. While these factors are frequent in low-/middle-income countries, because high-quality automotive engineering, road design and vehicles are continuously being optimized in developed countries in terms of safety, human causes are considered as the main causes of VRU traffic accidents. Thus, the number and incidence of traffic accidents involving VRU have different 
economic consequences in developing countries (low- and middle-income countries) and developed countries (high-income countries) [8].

Public policies (government budget and engagement for transport safety and the level of enforcement of road traffic rules), personal characteristics (health and physical condition, income, education, age and gender), socio-economic conditions (economic growth) and demographic and geographic circumstances (average distance traveled, the amount of time traveled and the population density) are factors that influence the rates of VRU traffic accidents [16]. Consequently, understanding these various factors and identifying their separate and/or combined effects on accident frequency and severity is important [11].

\subsection{Spatial Analysis of VRU Accidents}

To identify hotspots of road accidents (black spot zones) is important for determining effective strategies for reducing areas with a high density of accidents and for appropriately allocating resources for improving safety [32]. The characteristics of spatial analysis (GIS environment) for managing and processing locational and related information provide a robust understanding of the indicators of casual effects. Among several techniques, the KDE technique is one of the most frequently-used spatial tools for studying traffic accident phenomena, as demonstrated by [2,13,24,27,32-40].

The KDE technique is used to calculate the probability density function of a distribution from which a sample has been observed by centering a probability density function on each of the observed events [41]. The kernel estimator is a non-parametric algorithm that uses a density estimation method. This technique allows one to evaluate the local probability accident occurrence and, consequently, the probable dangerousness of a spatial unit [20]. KDE is the most widely-used nonparametric method in recent decades [42]. The KDE describes the distribution of the location of an event and ignores its association with values. This distribution is characterized by the density of events that occur around a centroid and represents the behavioral patterns of points or lines. In this study, the events are the locations (geocoded) of the accidents (represented by points), and the KDE is used to calculate the probability density function of each accident location.

Kernel density analysis is performed by passing a moving window over the data, usually on a regular grid. The densities of the observations within a set radius are calculated for each event located on the grid, and the contributions of each observation are weighted by its proximity to the center of the moving window. Thus, the result of applying KDE is a density map (raster format). The values of each pixel represent the relationships between the concentrations of the events per unit area. In addition, KDE can be used to calculate the density of punctual events (i.e., the density of traffic accidents in a region) or linear events (i.e., the density of a road network in a zone). It is important to highlight the simplicity, satisfactory properties and good results of the KDE method $[43,44]$.

The areas where events are concentrated are identified by KDE analysis and have the highest accident rates involving VRU. These areas are called black spots (zones that reveal concentrations of accidents). The existence of black spot zones results from the awareness of the spatial interactions between contiguous traffic accident locations. The most straightforward use of GIS for accident analysis is the examination of spatial characteristics and attributes of traffic accident locations. In fact, the use of GIS has several advantages of the use of non-spatial methods for accident analysis [45]. 
To determine the most significant variables in urban systems (sociodemographic and transport-related factors) that are involved in the occurrence of road accidents, several researchers have used multivariate regression analyses, including [46-56].

In this study, the quantity of VRU traffic accidents was regressed against the number of explanatory variables by using two models, the ordinary least squares (OLS) model and the spatial autoregressive lag (SAR) model.

The traditional OLS multiple regression model is relatively quick, simple and suitable for analyzing punctual events, such as road accidents. As a global regression method, an important assumption of the OLS model is that all variables are stationary across the study area. In addition, the OLS method can involve potential issues related to spatial and temporal autocorrelations, and the endogeneity between the dependent variable (amount of road accidents) and independent variables (such as, population, area, income, trips generated, etc.) is possible [57-59]. In turn, SAR is a strong modeling approach that can be adopted when a spatial autocorrelation is highly likely. In the SAR method, the interactions are modeled as a weighted average of the neighboring observations. The endogenous variables that comprise the interactions are called spatially-lagged dependent variables, and the weights, which are grouped into a neighborhood matrix (by contiguity or k nearest neighbors), form the distinctive core of the class of spatial process models. These two methods (OLS and SAR) provide comparisons across different specifications, tests for robustness and allow one to capture the importance of spatial interactions and interdependencies among the involved attributes $[60,61]$.

\section{Study Areas}

One study area is São Paulo City (Figure 1), which is the capital of São Paulo State and is located in Southeastern Brazil. São Paulo is an excellent example of a rapidly-growing city, with more than 11.3 million people (2013) in an area of $1521.101 \mathrm{~km}^{2}$, a demographic density of 7398.26 inhabitants $/ \mathrm{km}^{2}$, an urbanization rate of $99.10 \%$ (2010) and a geometric growth rate of $0.59 \%$ (during the period 2010-2013). According to the United Nations Organization (UNO), São Paulo is one of the 27 megacities in the world (source: IBGE_-Instituto Brasileiro de Geografia e Estatística).
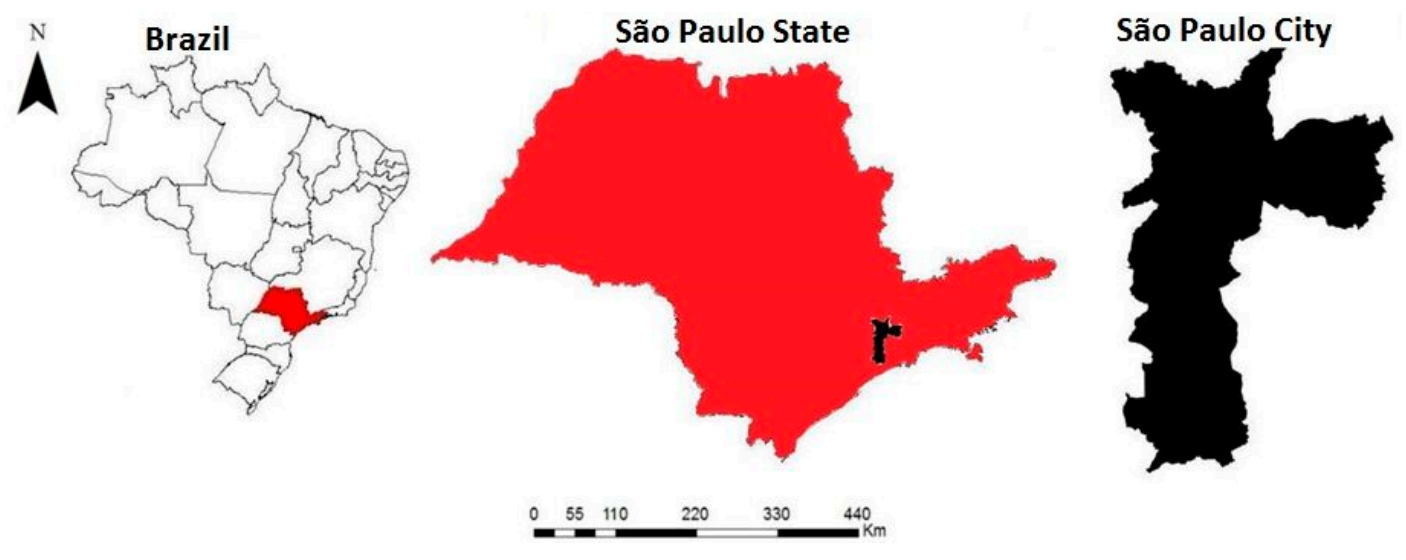

Figure 1. Study area: São Paulo. Source: [2].

The second study area, Rome (Figure 2), is a city and special commune (named "Roma Capitale") in Italy. Rome is the capital of Italy, the Province of Rome and the region of Lazio. Rome is Italy's 
largest and most populated commune and the fourth most populous city in the European Union. Its population (2013) is 2,913,349 inhabitants, with an area of $1285.31 \mathrm{~km}^{2}$ and a demographic density of 2266.7 inhabitants $/ \mathrm{km}^{2}$ (source: Roma Capitale, Annuario Statistico 2013, Unità Operative (U.O.) Statistica, Sistema Statistico Nazionale).

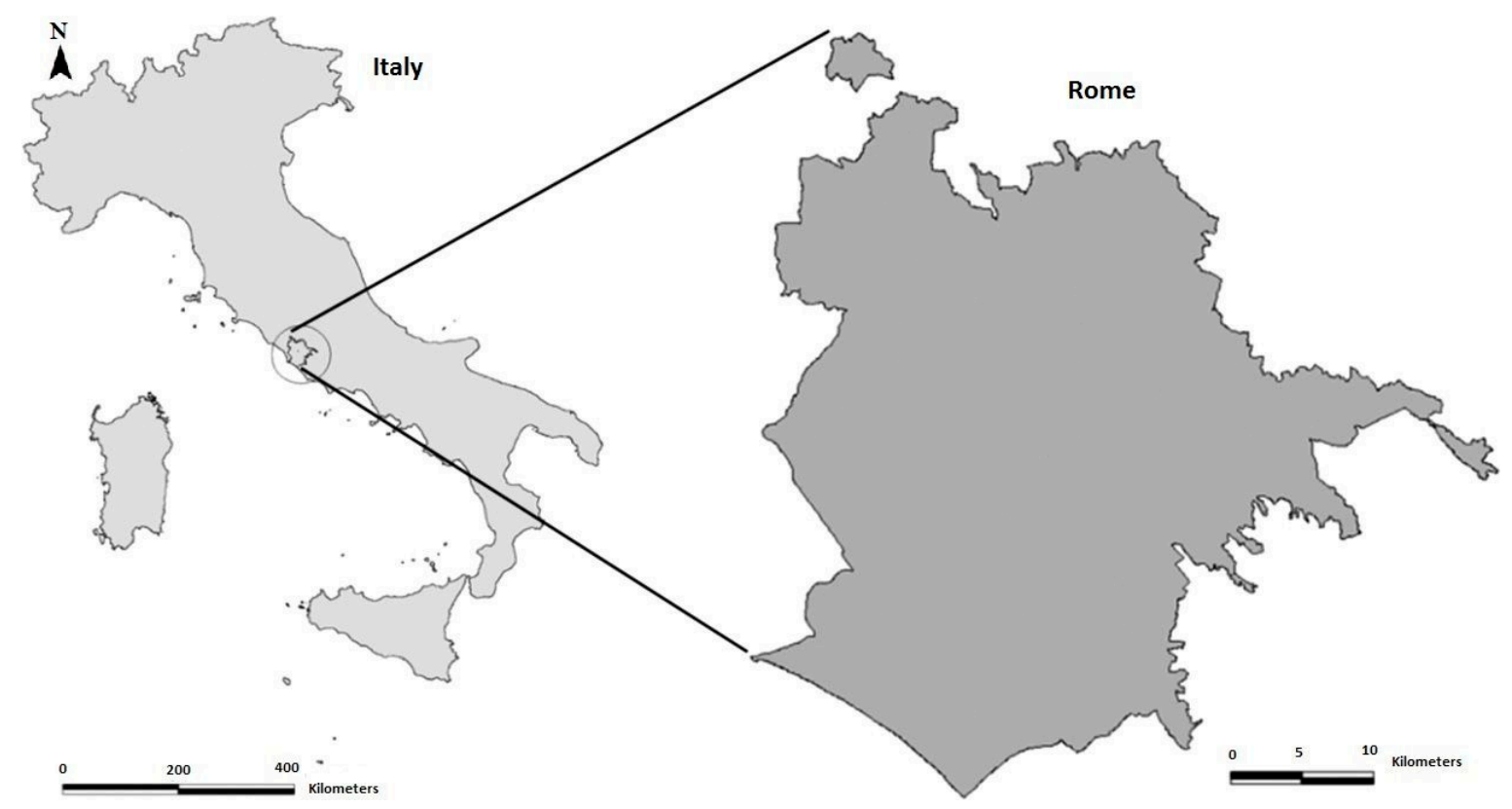

Figure 2. Study area: Rome. Source: Adapted from [62].

\section{Description of Data and Methods}

This study used a set of spatial and non-spatial data from São Paulo and Rome, which is described below.

\subsection{São Paulo}

The Municipality of São Paulo delivered the spatial unit adopted in the analysis (districts; Figure 3a) and the vectorial data (geocoded) that provided the locations of hospitals, universities and colleges, parks and recreational areas and retail shopping centers. The CET-SP (Companhia de Engenharia de Tráfego de São Paulo: the operative body of the municipality of São Paulo for traffic management of the city) provided the locations of traffic accidents involving VRUs in 2012 and in São Paulo's road network. Finally, the Metrô-SP (Companhia do Metropolitano do Estado de São Paulo: the public company responsible for operating the subway train system) performed the Origin and Destination Survey (2007 and 2012) that provided socioeconomic information and trip patterns.

\subsection{Rome}

The Research Center for Transport and Logistics (CLT) at the University of Rome delivered data regarding traffic accidents involving VRUs in 2012 with Rome's road network, socioeconomic information and vectorial data (geocoded), which provide the locations of hospitals, universities and colleges, parks and recreational areas and retail shopping centers. The spatial units adopted in this study are municipi, quartieri, rioni, suburbi and Zone Agro Romano (Figure 3b). 


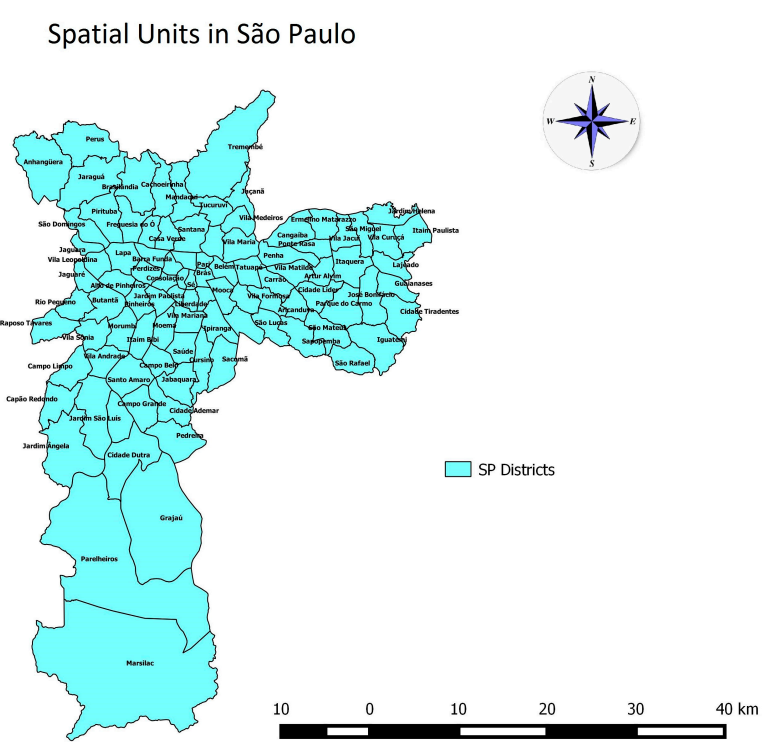

(a)

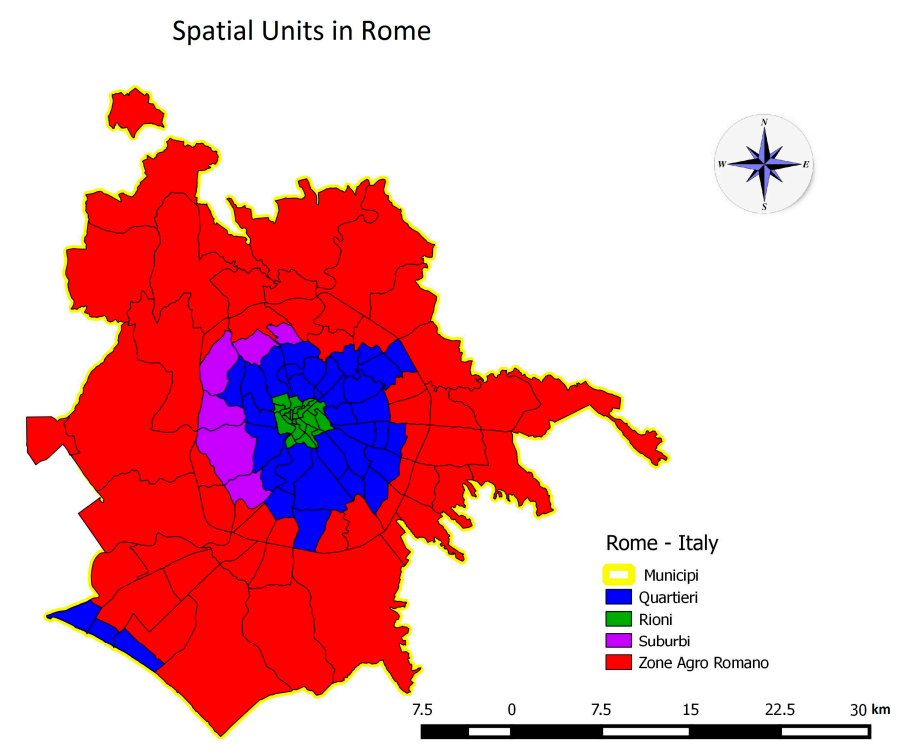

(b)

Figure 3. Spatial units: (a) São Paulo; and (b) Rome.

\subsection{Methodology}

The first step was to standardize the spatial data in terms of the coordinates systems, spatial units and spatial adjustment. Next, an analysis of VRU traffic accidents (total amount of accidents and the amount of fatal accidents, São Paulo and Rome; see Figure 4a,b) was performed in the GIS environment by using density analysis (KDE).

São Paulo VRU Traffic Accidents - 2012

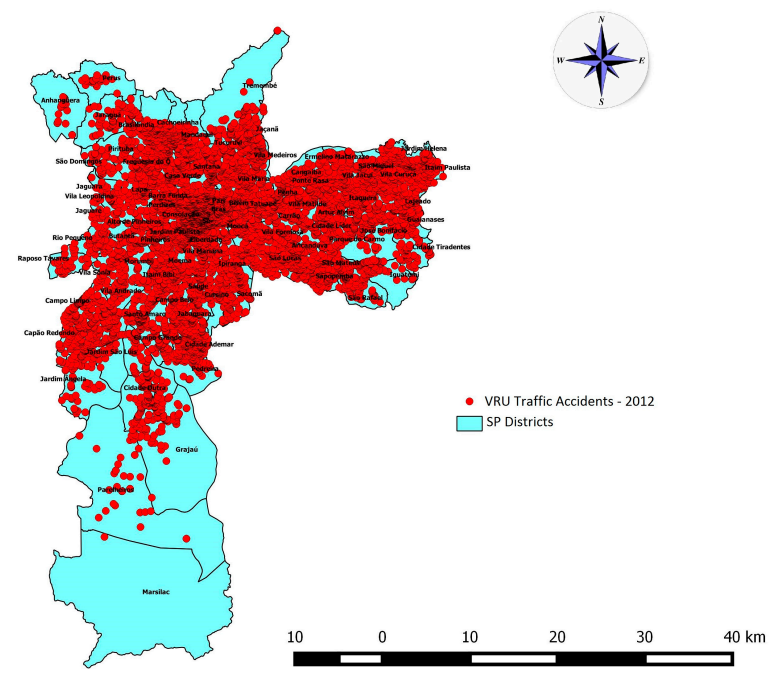

São Paulo VRU Fatal Accidents - 2012

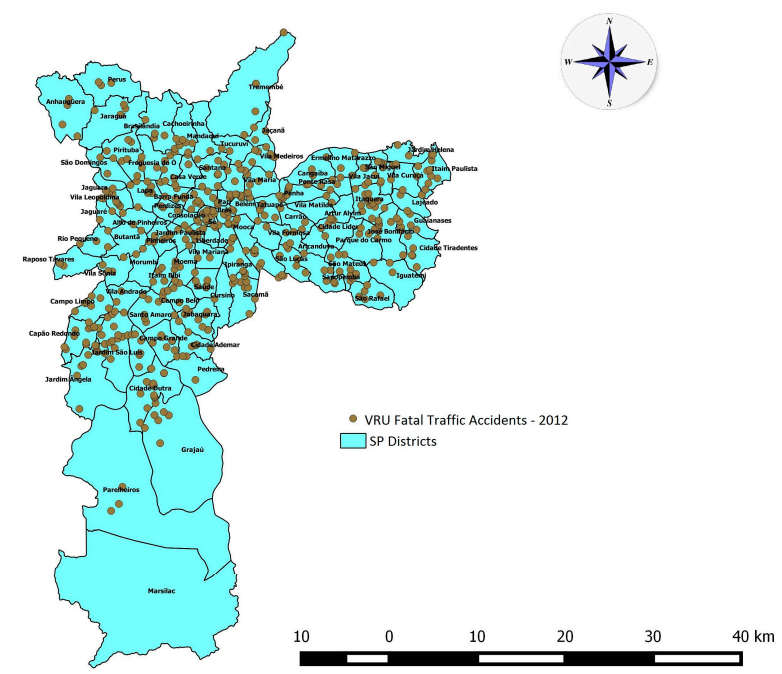

(a)

Figure 4. Cont. 

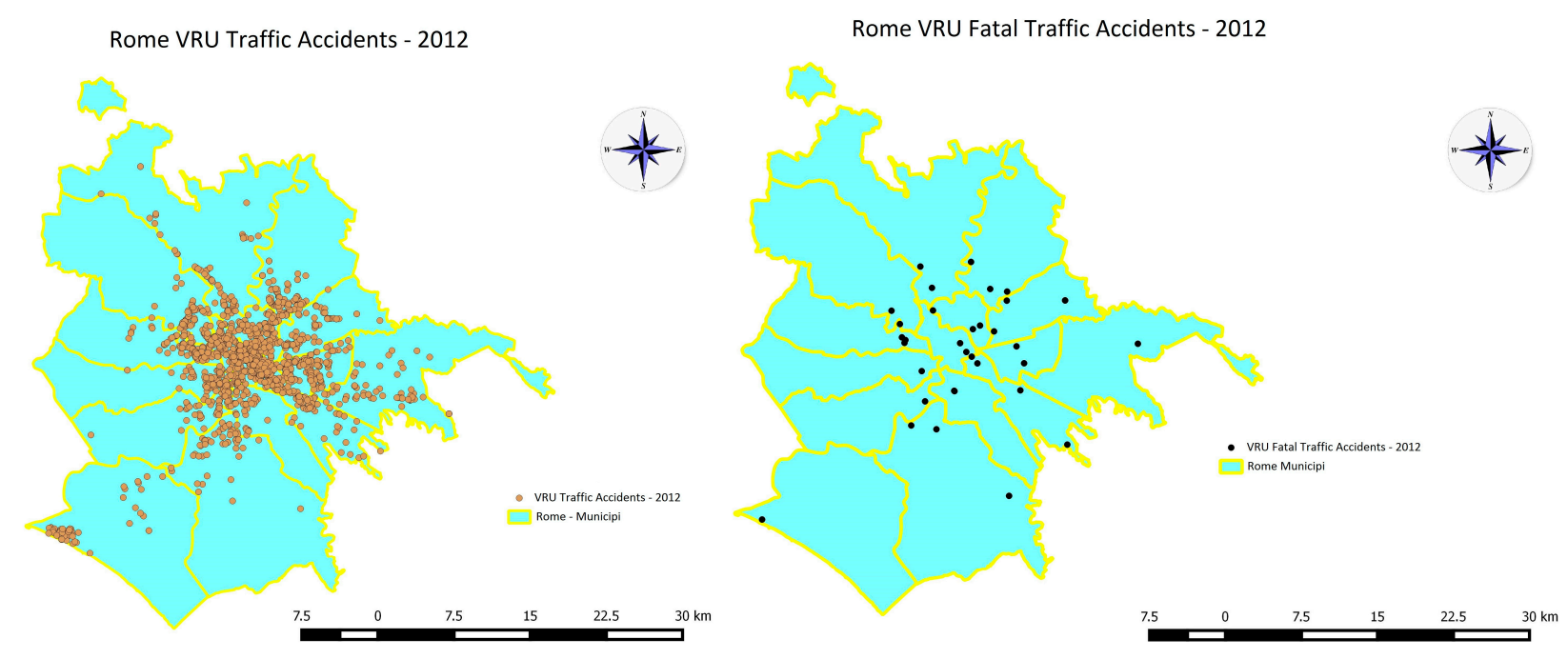

(b)

Figure 4. (a) Vulnerable road user (VRU) traffic accidents in São Paulo; (b) VRU traffic accidents in Rome.

The objectives of KDE analysis were to identify: (1) the spatial locations of black spots; (2) the attributes of each accident inside the black spot zones (address, road type, accident type, vehicle(s) involved and date/time); (3) the attributes of the region delimited by the black spots (area, population, demographic density and road network density); and (4) the number and spatial locations of the entities considered in this study as trip generator hubs (TGH) (hospitals, universities and colleges and retail shopping centers) inside the black spot zones.

An ecological study was conduct using data aggregated by spatial units (in São Paulo, districts; in Rome, quartieri, rioni, suburbi and Zone Agro-Romano; see Figure 3) to investigate the spatial clusters (black spot zones) and possible associations between the occurrences of urban road accidents and socio-economic and transport-related factors.

In the statistical analysis (spatial regression models), the following variables (in each spatial unit) were considered: the number of total and fatal VRU accidents; area; population; demographic density; the number of total/fatal accidents divided by area (VRU traffic accidents $/ \mathrm{km}^{2}$ ); the number of total/fatal accidents divided by the population (VRU traffic accident accidents/inhabitants); the number of generated trips; the number of generated trips divided by area $\left(\operatorname{trips} / \mathrm{km}^{2}\right)$; the number of generated trips divided by population (trips/inhabitant); average income; per capita income; the number of retail shopping centers, hospital and universities and colleges; and a variable named TGH (trip generator hubs), which is calculated as the sum of the number of retail shopping centers, hospitals and universities and colleges. The first step was to calculate the correlation matrix (Spearman correlations) to identify collinear variables and to remove them from the regression model (correlation greater than $60 \%$ ).

A regression analysis (OLS method) of the amount of total/fatal accidents divided by area (dependent variables) with the selected independent variables was performed. The variables incorporated in the model were selected by assessing the significance level ( $p$-value). Possible explanatory variables were defined as those that presented $p$-values of $\leq 0.20$ [63]. A global spatial analysis was also performed to verify the spatial dependence and variability around the predicted value (i.e., the spatial distribution and heterogeneity in model residuals) [64]. The importance of normal distributions is undeniable when 
applying regression models, because interpretation and inferences may not be reliable or valid when the normality assumption is violated [65]. Next, the Kolmogorov-Smirnov test for normality was performed, as described by [66].

Global Moran's Index is the most commonly-used test for global spatial autocorrelation [67], was determined for regression residuals (for more details, see [68]) to investigate the impacts of neighborhood matrix type and was used as a queen type of regular contiguity matrix (for more details, see [69]. When the Global Moran's Index does not present a significant positive spatial autocorrelation, the OLS model is considered appropriate. Otherwise, a two-step Lagrange Multiplier Test (LMT) is applied to reveal spatial dependence and spatial heterogeneity. In this study, when the Moran's Index indicates that the residuals present spatial dependence, the SAR model (for more details, see [70]) was used.

\section{Results}

\subsection{Kernel Density Estimator}

The first analysis was the KDE, which was used in a GIS environment to identify black spot zones of traffic accidents (the total number of accidents and fatal accidents) involving pedestrians and cyclists. Due to the high number of road accidents in São Paulo (as shown in Figure 4a), the KDE generated four representative density classes for total accidents, low-, medium-, high- and very high-density accident areas (Figure 5). In addition, three density classes were generated for fatal accidents (Figure 6). In Rome, the quantity of road accidents was much lower than in São Paulo (Figure 4b). Thus, the KDE generated three density classes for total and fatal accidents, low-, medium- and high-density accident areas (Figures 7 and 8).

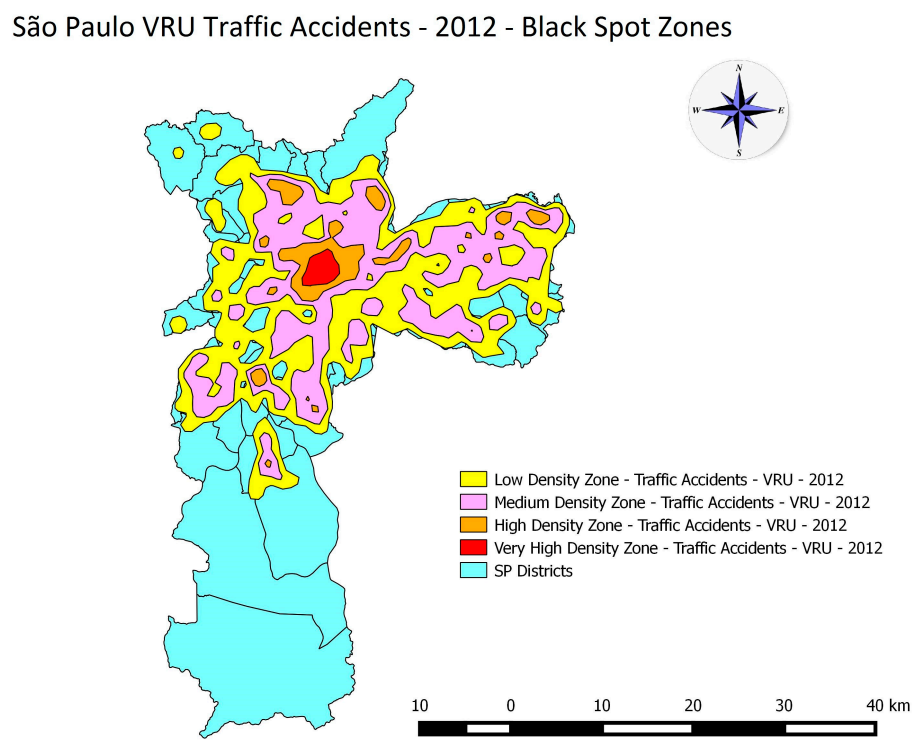

Figure 5. Black spot zones. Traffic accidents involving VRU in São Paulo in 2012. 
São Paulo VRU Fatal Traffic Accidents - 2012 - Black Spot Zones

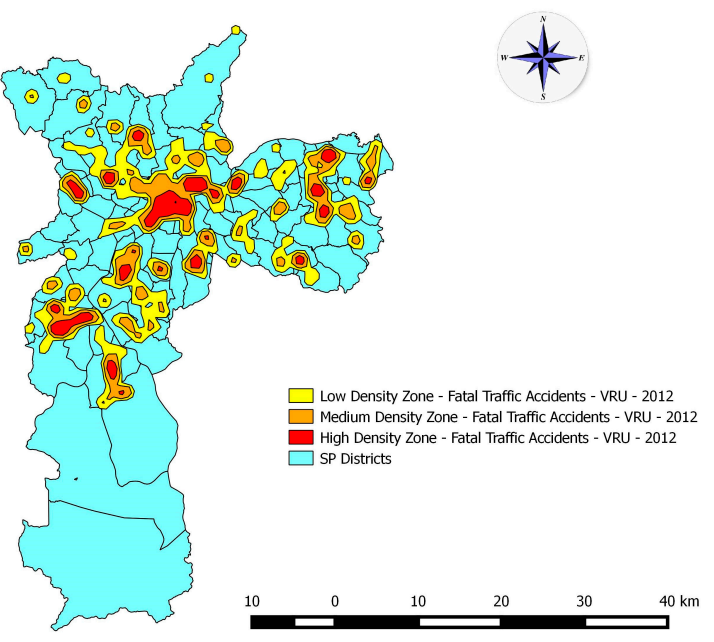

Figure 6. Black spot zones. Fatal traffic accidents involving VRU in São Paulo in 2012.

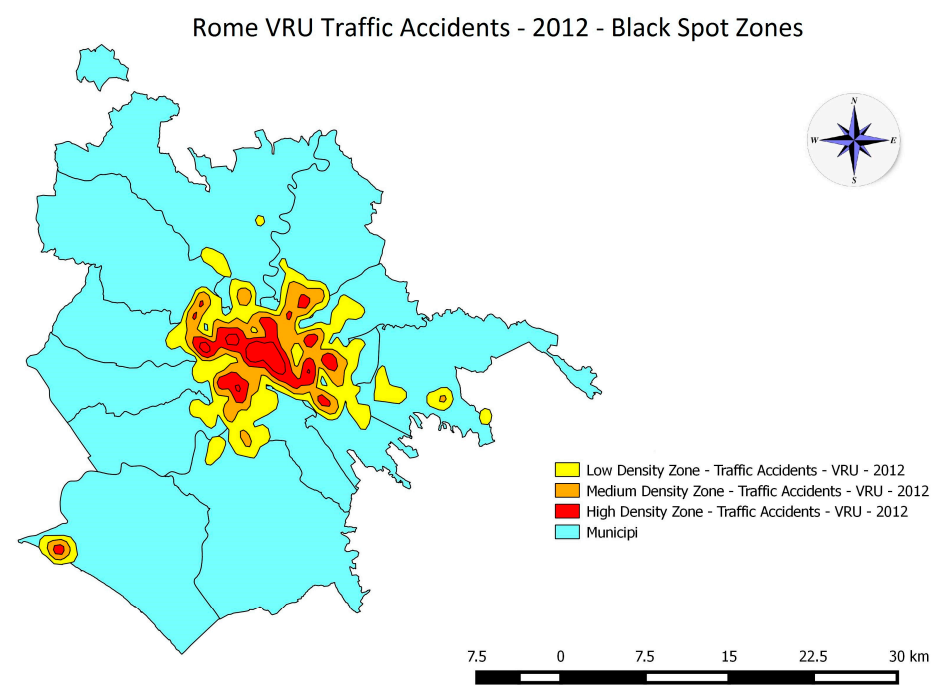

Figure 7. Black spot zones. Traffic accidents involving VRU in Rome in 2012.

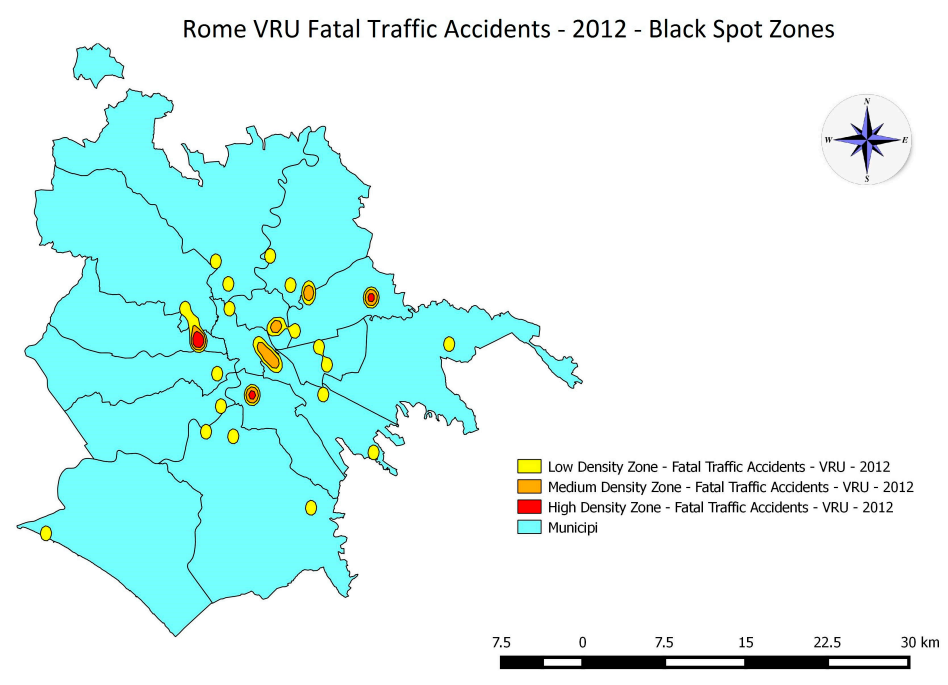

Figure 8. Black spot zones. Fatal traffic accidents involving VRU in Rome in 2012. 


\subsection{Statistical Analysis}

The black spot zones were linked to the presence of TGH ((1) hospitals; (2) universities and colleges; and (3) retail shopping centers). Figures 9-11 show the presence of TGH inside the density zones in São Paulo, and Figures 12-14 show those of Rome.

São Paulo - Hospitals - Black Spot Zones

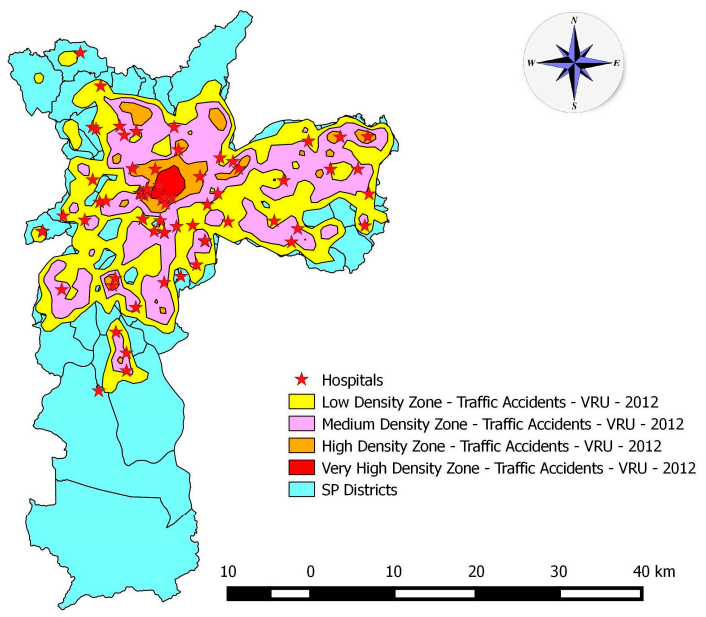

São Paulo - Hospitals - Fatal Black Spot Zones

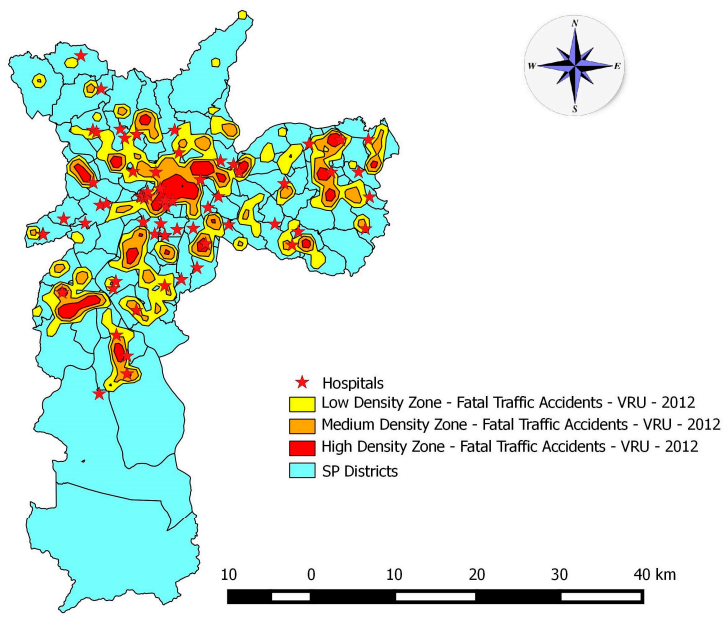

Figure 9. Hospitals/black spot: São Paulo.

São Paulo - Universities - Black Spot Zones

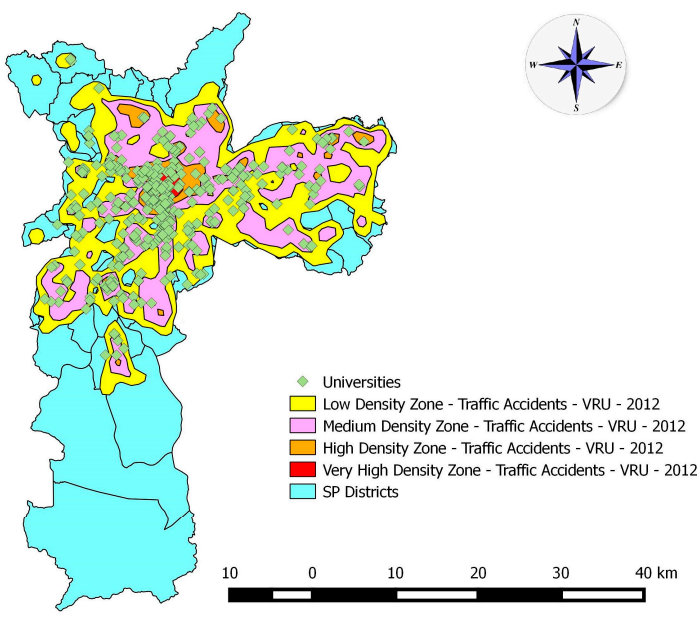

São Paulo - Universities - Fatal Black Spot Zones

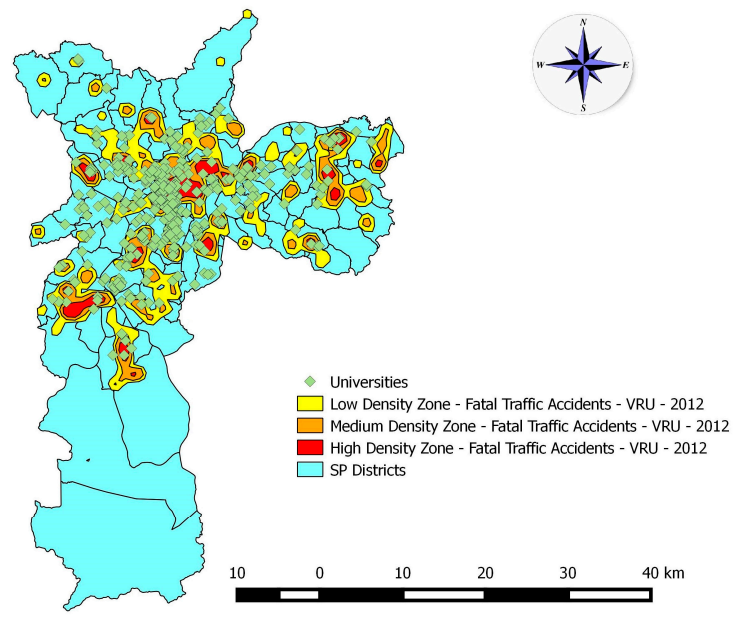

Figure 10. Universities /black spots: São Paulo. 

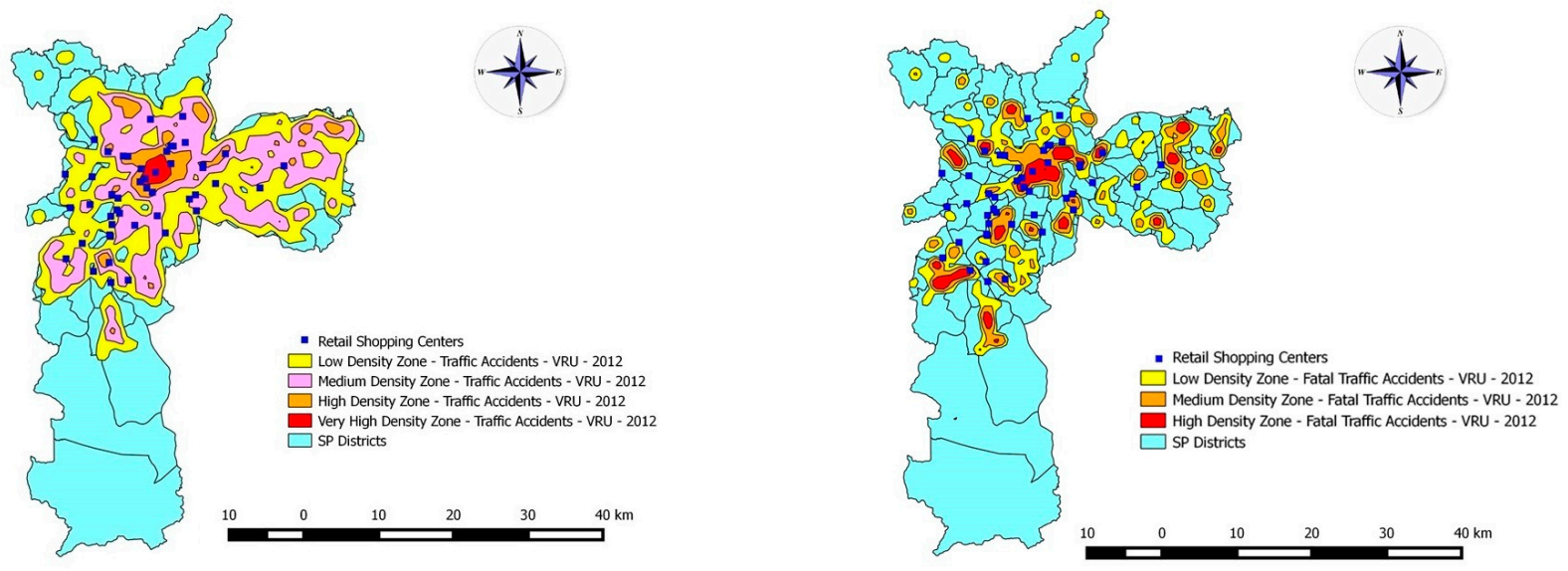

Figure 11. Retail shopping centers/black spots: São Paulo.

Rome - Hospitals - Black Spot Zones Rome - Hospitals - Fatal Black Spot Zones
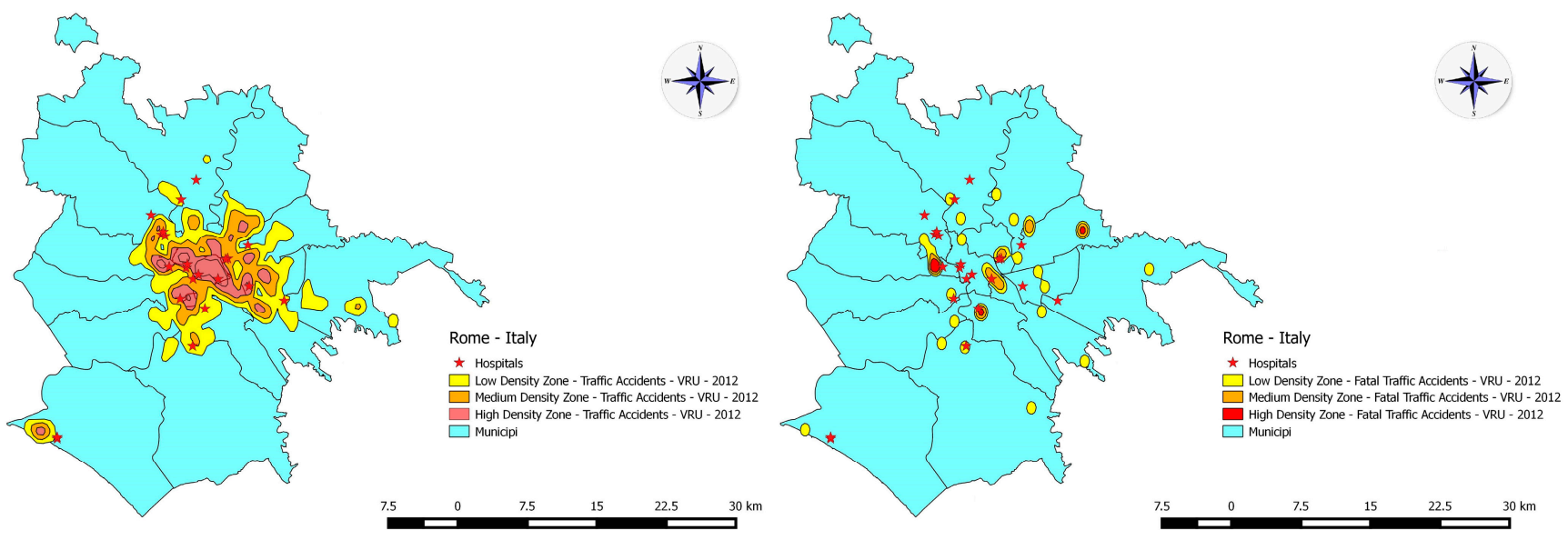

Figure 12. Hospitals/black spot: Rome.

Rome - Universities - Black Spot Zones Rome - Universities - Fatal Black Spot
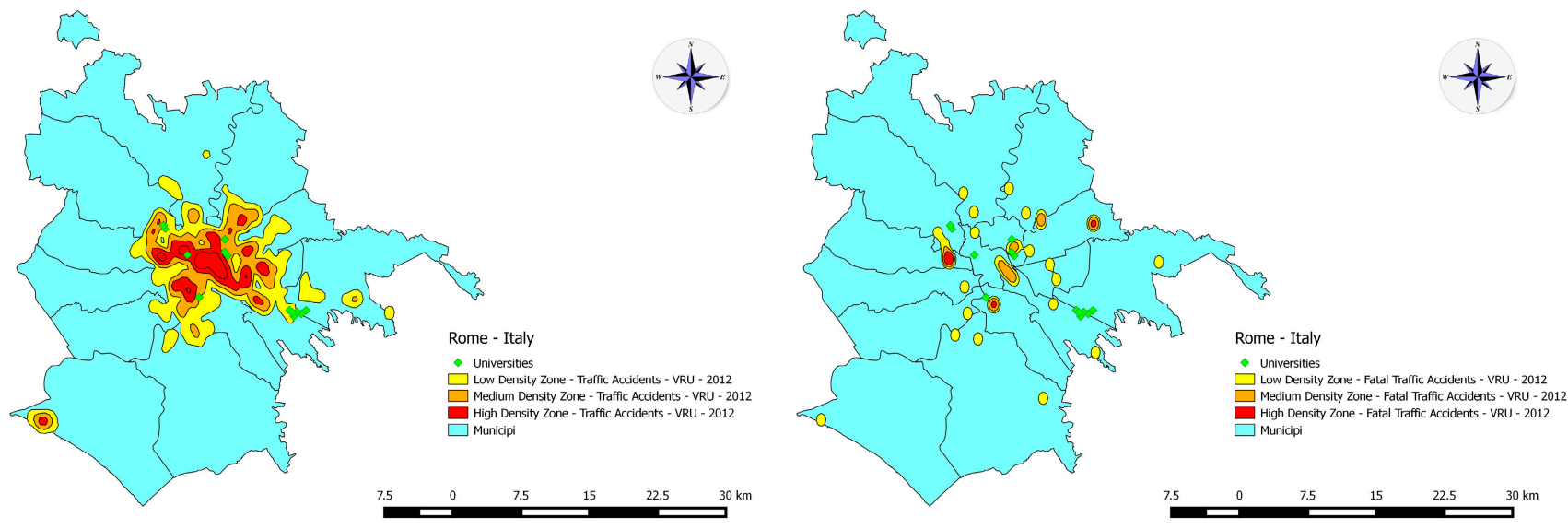

Figure 13. Universities and colleges/black spots: Rome. 


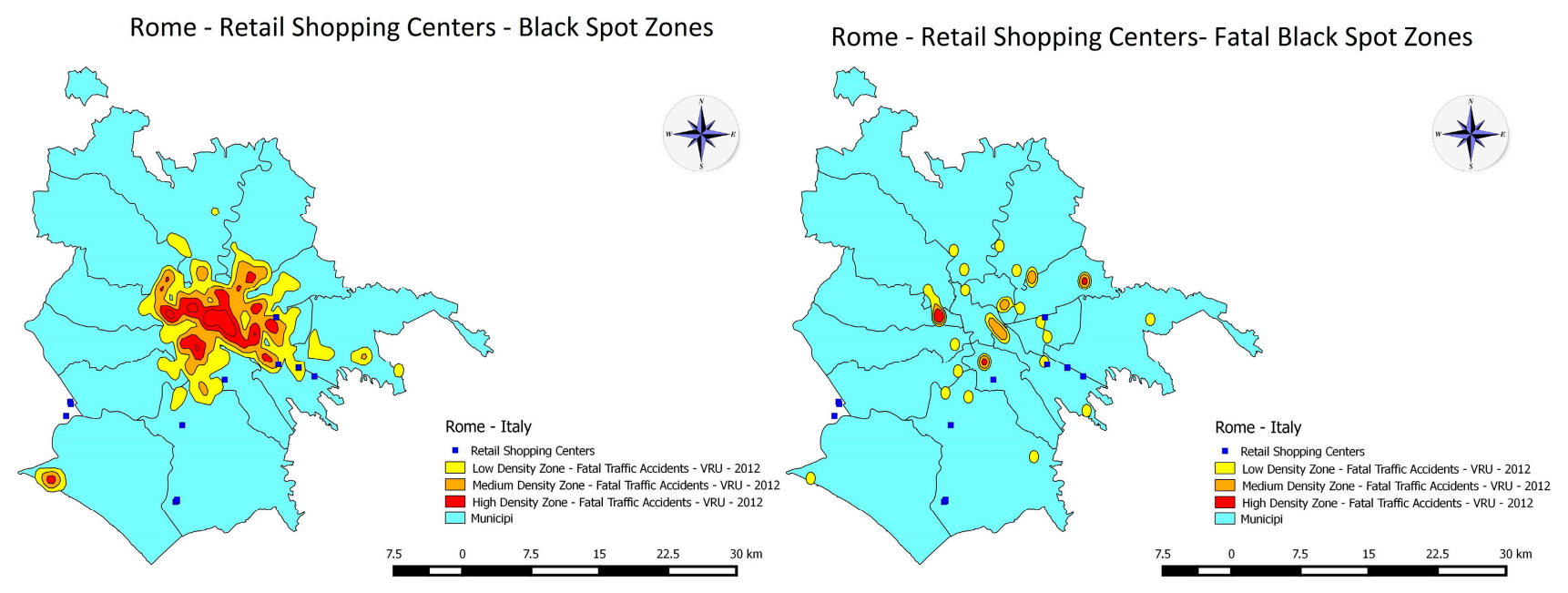

Figure 14. Retail shopping centers/black spots: Rome.

A visual analysis alone is not sufficient for affirming the existence of direct influences of TGH over black spot zones. Thus, we investigated whether the concentrations of these entities (TGH) are related by using high rates of traffic accidents in both cities and determined the variables that could be associated with the occurrences of these events.

\subsubsection{São Paulo: Total VRU Traffic Accidents}

In São Paulo, the explanatory variables that best explained the concentrations of total VRU traffic accidents (represented in the model by the rate number of total traffic accidents divided by area) included the number of generated trips divided by population (trips/inhabitant) and THG (retail shopping centers + hospitals + universities/colleges). The Kolmogorov-Smirnov test was used to assess the normality, and the fourth root of the total VRU traffic accidents was used to improve the normal distribution approximation. The results are presented below in Table 1 and show that the OLS model is appropriate.

Table 1. OLS regression model: São Paulo, total VRU traffic accidents.

\begin{tabular}{|c|c|c|c|c|}
\hline Explanatory Variable & Regression Coefficient & Standard Error & $t$-Value & $p$-Value \\
\hline Intercept & 1.3852 & 0.0618 & 22.434 & 0.0000 \\
\hline Trips/inhabitants & 0.0352 & 0.0098 & 3.575 & 0.0006 \\
\hline TGH (Trip Generator Hub) & 0.0140 & 0.0045 & 3.084 & 0.0027 \\
\hline \multicolumn{5}{|c|}{ Residual standard error: 0.3611} \\
\hline \multicolumn{5}{|c|}{ Multiple R-squared: 0.2906} \\
\hline \multicolumn{5}{|c|}{ Adjusted R-squared: 0.2754} \\
\hline \multicolumn{5}{|c|}{ F-statistic: 19.05} \\
\hline \multicolumn{5}{|c|}{$p$-value: 0.0000} \\
\hline \multicolumn{5}{|c|}{ Residual analysis: } \\
\hline \multicolumn{5}{|c|}{ Observed Moran's Index: -0.0221} \\
\hline \multicolumn{5}{|c|}{$p=0.8609$ (Moran test) } \\
\hline \multicolumn{5}{|c|}{ Expectation: -0.0106} \\
\hline \multicolumn{5}{|c|}{ Variance: 0.0043} \\
\hline \multicolumn{5}{|c|}{ Kolmogorov-Smirnov test: $p=0.1651$} \\
\hline
\end{tabular}




\subsubsection{São Paulo: Fatal VRU Traffic Accidents}

In São Paulo, the explanatory variable that best explained the concentration of fatal VRU traffic accidents (represented in the model by the rate number of fatal traffic accidents divided by area) was calculated as the generated trips divided by the population (trips/inhabitant). The Kolmogorov-Smirnov test was used to assess normality, and the square root of fatal VRU traffic accidents was used to improve the approximation of the normal distribution. The results are presented below in Table 2 and show that the OLS model is appropriate.

Table 2. OLS regression model: São Paulo, fatal VRU traffic accidents.

\begin{tabular}{|c|c|c|c|c|}
\hline Explanatory Variable & Regression Coefficient & Standard Error & $t$-Value & $p$-Value \\
\hline Intercept & 0.4134 & 0.0513 & 8.051 & 0.0000 \\
\hline Trips/inhabitants & 0.0426 & 0.0076 & 5.601 & 0.0000 \\
\hline \multicolumn{5}{|c|}{ Residual standard error: 0.3078} \\
\hline \multicolumn{5}{|c|}{ Multiple R-squared: 0.2502} \\
\hline \multicolumn{5}{|c|}{ Adjusted R-squared: 0.2423} \\
\hline \multicolumn{5}{|c|}{ F-statistic: 31.37} \\
\hline \multicolumn{5}{|c|}{$p$-value: 0.0000} \\
\hline \multicolumn{5}{|c|}{ Residual analysis: } \\
\hline \multicolumn{5}{|c|}{ Observed Moran's Index: 0.1051} \\
\hline \multicolumn{5}{|c|}{$p=0.0664$ (Moran test) } \\
\hline \multicolumn{5}{|c|}{ Expectation: -0.0138} \\
\hline \multicolumn{5}{|c|}{ Variance: 0.0042} \\
\hline \multicolumn{5}{|c|}{ Kolmogorov-Smirnov test: $p=0.6124$} \\
\hline
\end{tabular}

\subsubsection{Rome: Total VRU Traffic Accidents}

In Rome, the explanatory variable that best explains the concentration of total VRU traffic accidents is demographic density (inhabitants $/ \mathrm{km}^{2}$ ). The Kolmogorov-Smirnov test was used to assess the normality, and the square root of the total VRU traffic accidents was used to improve the approximation of the normal distribution. The results are presented below in the Table 3 and show that the OLS model is not appropriate. Then, the next step was the application of the SAR model.

Since Moran's Index is a significant value, the residuals present spatial dependence, and the OLS is not appropriate for modeling Rome's total VRU traffic accidents. Thus, the Lagrange Multiplier Test (LMT) was performed to select the best model. The results are shown in Table 4. When analyzing the LMT results, the Robust Lagrange Multiplier Spatially-Lagged (RLMlag) model was adopted.

The spatial autocorrelation lag model (RLMlag) results are presented in Table 5 and show that the SAR model is appropriate, because no residual spatial dependence occurs. The Akaike Information Criterion (AIC) (details in [71-73]) of the SAR model is lower than the AIC of the linear regression (OLS), which demonstrates that the SAR model is better than the OLS model for total VRU traffic accidents in Rome. 
Table 3. OLS regression model: Rome, total VRU traffic accidents.

\begin{tabular}{|c|c|c|c|c|}
\hline Explanatory Variable & Regression Coefficient & Standard Error & $t$-Value & $p$-Value \\
\hline Intercept & 0.6570 & 0.1627 & 4.038 & 0.0000 \\
\hline Demographic Density & 0.0002 & 0.000002 & 10.589 & 0.0000 \\
\hline \multicolumn{5}{|c|}{ Residual standard error: 1.317} \\
\hline \multicolumn{5}{|c|}{ Multiple R-squared: 0.4959} \\
\hline \multicolumn{5}{|c|}{ Adjusted R-squared: 0.4915} \\
\hline \multicolumn{5}{|c|}{ F-statistic: 112.1} \\
\hline \multicolumn{5}{|c|}{$p$-value: 0.0000} \\
\hline \multicolumn{5}{|c|}{ Residual analysis: } \\
\hline \multicolumn{5}{|c|}{ Observed Moran's Index: 0.3758} \\
\hline \multicolumn{5}{|c|}{$p=0.0000($ Moran test $)$} \\
\hline \multicolumn{5}{|c|}{ Expectation: -0.0113} \\
\hline \multicolumn{5}{|c|}{ Variance: 0.0022} \\
\hline \multicolumn{5}{|c|}{ Kolmogorov-Smirnov test: $p=0.7016$} \\
\hline
\end{tabular}

Table 4. Lagrange Multiplier Test (LMT): Rome, total VRU traffic accidents.

\begin{tabular}{ccc}
\hline Test & Statistic Value & $\boldsymbol{p}$-Value \\
\hline Lagrange Multiplier Error-LMerr & 0.1058 & 0.0000 \\
Lagrange Multiplier Spatially-Lagged_LMlag & 3.1272 & 0.0000 \\
Robust Lagrange Multiplier Error-RLMerr & 5.9186 & 0.2344 \\
Robust Lagrange Multiplier Spatially-Lagged_RLMlag & 8.9401 & 0.0000 \\
Spatial Autoregressive Moving Average_-SARMA & 9.0458 & 0.0109 \\
\hline
\end{tabular}

Table 5. Spatial autocorrelation (SAR) lag model: Rome, total VRU traffic accidents.

\begin{tabular}{ccccc}
\hline Explanatory Variable & Regression Coefficient & Standard Error & $\boldsymbol{z}$-Value & $\boldsymbol{p}$-Value \\
\hline Intercept & -0.1444 & 0.1501 & 0.9616 & 0.3363 \\
Demographic Density & 0.0001 & 0.0000 & 7.9150 & 0.0000 \\
\hline
\end{tabular}

Rho: 0.63342

Likelihood Ratio Test - LR test value: 68.206

$p$-value: 0.0000

Asymptotic standard error: 0.068453

$z$-value: 9.2533

Wald statistic: 85.624

Log likelihood: -161.426 for lag model

ML residual variance (sigma squared): 0.88966 (sigma: 0.94322)

AIC: 330.85 (AIC for linear regression: 397.06)

LM test for residual autocorrelation

test value: 7.5693

p-value: 0.005937 
Table 5. Cont.

\begin{tabular}{c} 
Residual analysis: \\
Observed Moran's Index: -0.1040 \\
$p=0.9794$ (Moran test) \\
Expectation: -0.0087 \\
Variance: 0.0022 \\
Moran I statistic standard deviation $=-2.0413$ \\
$p$-value: 0.9794 \\
\hline
\end{tabular}

\subsubsection{Rome: Fatal VRU Traffic Accidents}

Due to the low occurrence of fatal traffic accidents involving VRU in Rome (only 34 events), it was not possible to perform a statistical analysis by using standard spatial regression models. In this case, it is necessary to adopt a zero-inflated model (a situation of excess zeros relative to what the standard models allow), because a large number of observations are equal to zero, as described in [74]. According to [75], zero-inflated count data refer to data for which a generalized linear model has a lack of fit due to too many zeros. Such data are common in many applications (in this study, the research involving urban road accidents), especially when many subjects have zero observations. However, many applications have much larger observations, so that the overall mean is not near zero. Thus, the VRU traffic fatal accidents in Rome were not statistically analyzed.

\section{Conclusions}

The use of spatial analysis (KDE method in a GIS environment) presented satisfactory results to identify and delimit zones with high concentrations of VRU traffic accidents. Using the black spots zones, it was possible to classify subzones with different degrees of density (very high/high/medium/low density).

When analyzing the obtained results from São Paulo, the areas with the highest VRU traffic accident rates corresponded with the areas with the highest concentrations of TGH, including hospitals, universities and colleges and retail shopping centers. Figure 9 shows that the area around the hospitals presents the highest risk of VRU traffic accidents. Similarly, Figure 10 illustrates that "very high-density", "high-density" and "medium-density" black spot zones were mainly where universities and colleges are concentrated. The same result can be noticed regarding retail shopping centers (Figure 11).

The statistical analysis of São Paulo revealed an association between the dependent variable (number of VRU total/fatal traffic accidents divided by area) and the independent variables (the ratio trips/inhabitants and the presence of TGH). In turn, the regression model demonstrated that the presence of TGH does not decisively influence the occurrence of fatal VRU traffic accidents, as observed for total accidents (sum of non-fatal and fatal accidents). In terms of fatal VRU accidents, the explanatory variable that presented the highest association was the number of generated trips (trips/inhabitants). In both cases (total and fatal accidents), the OLS model is appropriate for describing the dynamics of VRU traffic accidents and the characteristics of the city (area, population, income, generated trips, TGH, etc.).

According to the visual analysis in Rome, it is not possible to affirm that black spot zones are connected with the preferred destinations of the population (TGH). The statistical analysis showed that the variable "demographic density" is sufficient for explaining the dynamics of total VRU road accidents. 
Because Rome is one of the most visited cities in the world and has a large number and variety of historical and touristic attractions that are located in its central area, one possible cause of the high VRU traffic accident rates in these zones could be the high concentration of visitors rather than the presence of traditional trip generator hubs. However, no pattern was observed regarding the TGH. Thus, it is not possible to establish a direct correlation between the presence of trip generator hubs and VRU traffic accident rates in Rome.

\section{Final Considerations}

According to [76,77], motorized transport modes account for most road accidents in many urban areas. Thus, the development of alternative transport methods, such as mass transit, bicycles and walking, has often been recommended. However, policies directed at such implementations have barely taken off in Rome and São Paulo or for the development of proper safety guidelines for VRU.

Road traffic injuries in Rome are the principal cause of death among young people (14-30 years of age). Managing traffic speed remains crucial for creating a safe road system and for achieving the European Union (EU)-imposed target of reducing road fatalities by 50\% in 2011-2020 [78,79].

Similarly, traffic accidents are the main cause of injury and fatalities among children (above one year old) and teenagers (up to 19 years old) in São Paulo [80]. According to [81,82], the number of traffic accidents is related to fast and uncontrolled urban growth in São Paulo. The proportion of fatal crashes involving VRU partly results from cultural and sociodemographic factors. Many fatal traffic accidents or accidents with severe injuries are caused by poor traffic safety conditions, which are often accentuated by physical, political, technical and enforcement environments.

Speed enforcement systems should be adopted to reduce urban road accidents, and the geometric characteristics of the road network should be re-evaluated and modified [83]. One method for reaching these goals is to introduce cost-effective practices, such as traffic calming strategies that benefit the mobility of VRU by reducing the speed of motorized traffic, re-designing transport infrastructure and introducing cycling and walking facilities [84].

Traffic calming refers to a combination of physical changes in road design and speed management that is aimed at improving road safety conditions, especially for users of non-motorized modes (VRU) [85]. Traffic calming measures influence road safety by reducing vehicle speed and/or the volumes of traffic on urban road systems, reducing and/or eliminating conflicting movements, improving visibility, reducing exposure and sharpening drivers' alertness [86]. Traffic calming measures include chicanes, central islands, traffic control devices (e.g., variable message signs or speed cameras), surface treatments (e.g., speed humps or transverse rumble strips) and roadside features (e.g., gateways or landscaping).

The high socio-economic costs of traffic accidents clearly indicate the need for governments and policymakers to strengthen traffic accident preventive measures [87]. According to [78,88], one of the most important intervention methods is educational action, which should be directed at the entire population and especially at adolescents and young adults, which are at higher risk for involvement in traffic accidents. The behaviors of users (drivers and passengers of motorized and non-motorized vehicles and pedestrians) can interfere with the number and severity of traffic accidents, particularly speeding, poor driving skills and education, lack of familiarity with non-motorized transportation modes, lacking the use of safety equipment (seat belt, motorcycle helmet, etc.) and alcohol consumption. 


\section{Acknowledgments}

The authors would like to thank the Centro di Ricerca per il Trasporto e la Logistica (Research Centre for Transport and Logistics) at the University of Rome, especially Francesco Filippi, for providing the dataset for Rome and the CET-SP (Companhia de Engenharia de Tráfego de São Paulo, the Traffic Engineering Company of São Paulo) for providing the traffic accident data for São Paulo. In addition, the authors thank the CNPq (Conselho Nacional de Desenvolvimento Científico e Tecnológico, the National Council for Scientific and Technological Development) and FUSP (Fundação da Universidade de São Paulo, the Foundation of the University of São Paulo) for granting scholarships to the researchers and the Laboratory of Geoprocessing in the Department of Transportation Engineering at the Polytechnic School of the University of São Paulo for providing the infrastructure used for this study.

\section{Author Contributions}

All the authors conceived the study and contributed to the manuscript. C.A.S.M., M.A.G., J.A.Q., A.T., and L.P. performed the spatial analysis. F.C.N. and C.A.S.M. provided the statistical analysis. C.A.S.M. wrote the paper. J.A.Q. and L.P. served as supervisors for this work, respectively in São Paulo (Brazil) and Rome (Italy), and revised the manuscript. All authors read and approved the final manuscript

\section{Conflicts of Interest}

The authors declare no conflict of interest.

\section{References}

1. Haque, M.M.; Chin, H.C.; Debnath, A.K. Sustainable, safe, smart-Three key elements of Singapore's evolving transport policies. Transp. Policy 2013, 27, 20-31.

2. Machado, C.A.S.; Giannotti, M.A.; Shinohara, E.J.; Nishisaki, H.; Quintanilha, J.A. Characterization of the sites of traffic accidents involving vulnerable road users (VRU) in São Paulo city. In Proceedings of the Transport Research Arena (TRA 2014) - 5th Conference Transport Solutions: From Research to Deployment-Innovative Mobility, Mobilise Innovation, Paris, France, 14-17 April 2014; p.10.

3. Santos, G.; Behrendt, H.; Maconi, L.; Shirvani, T.; Teytelboym, A. Part I: Externalities and economic policies in road transport. Res. Transp. Econ. 2010, 28, 2-45.

4. Small, K.; Verhoef, E.T. The Economics of Urban Transportation; Routledge: London, UK, 2007; p. 276.

5. Suzuki, H.; Cervero, R.; Iuchi, K. Transforming Cities with Transit-Transit and Land-Use Integration for Sustainable Urban Development; Urban Development Series; The World Bank: Washington, DC, USA, 2013; p. 205.

6. Klassen, J.; El-Basyouny, K.; Islam, M.T. Analyzing the severity of bicycle-motor vehicle collision using spatial mixed logit models: A city of Edmonton case study. Saf. Sci. 2014, 62, 295-304.

7. Nabors, D.; Goughnour, E.; Thomas, L.; Desantis, W.; Sawyer, M. Bicycle road safety audit guidelines and prompt lists. In Federal Highway Administration-FHWA, Final Report; FHWA: Washington, DC, USA, 2012; p. 88. 
8. Otte, D.; Jänsch, M.; Haasper, C. Injury protection and accident causation parameters for vulnerable road users based on German In-Depth Accident Study GIDAS. Accid. Anal. Prev. 2012, $44,149-153$.

9. Schepers, P.; Hagenzieker, M.; Methorst, R.; van Wee, B.; Wegman, F. A conceptual framework for road safety and mobility applied to cycling safety. Accid. Anal. Prev. 2014, 62, 331-340.

10. Jiang, B.; Okabe, A. Different ways of thinking about street networks and spatial analysis. Geogr. Anal. 2014, 46, 341-344.

11. Theofilatos, A.; Yannis, G. A review of the effect of traffic and weather characteristics on road safety. Accid. Anal. Prev. 2014, 72, 244-256.

12. Çela, L.;Shiode, S.; Lipovac, K. Integrating GIS and spatial analytical techniques in an analysis of road traffic accidents in Serbia. Int. J. Traffic Transp. Eng. 2013, 3, 1-15.

13. Bíl, M.; Andrášik, R.; Janoška, Z. Identification of hazardous road locations of traffic accidents by means of kernel density estimation and cluster significance evaluation. Accid. Anal. Prev. 2013, $55,265-273$.

14. Wang, C.; Quddus, M.A.; Ison, S.G. The effect of traffic and road characteristics on road safety: A review and future research direction. Saf. Sci. 2013, 57, 264-275.

15. World Health Organization (WHO). World Report on Road Traffic Injury Prevention; Peden, M., Scurfield, R., Sleet, D., Mohan, D., Hyder, A.A., Jarawan, E., Mathers, C., Eds.; WHO: Geneva, Switzerland, 2004; p. 217.

16. Moeinaddini, M.; Asadi-Shekari, Z.; Shah, M.Z. The relationship between urban street networks and the number of transport fatalities at the city level. Saf. Sci. 2014, 62, 114-120.

17. World Health Organization (WHO). Global Status Report on Road Safety 2013-Supporting a Decade of Action; WHO: Geneva, Switzerland, 2013; p. 318.

18. Ministry of Healthy. 2013. Available online: http://www2.datasus.gov.br/DATASUS/index.php? area $=0205 \& \mathrm{VObj}=\mathrm{http} / /$ tabnet.datasus.gov.br/cgi/deftohtm.exe?sim/cnv/ext10 (accessed on 6 May 2013).

19. Koh, P.P.; Wong, Y.D. Comparing pedestrians' needs and behaviours in different land use environments. J. Transp. Geogr. 2013, 26, 43-50.

20. Flahaut, B.; Mouchart, M.; San Martin, E.; Thomas, I. The local spatial autocorrelation and the kernel method for identifying black zones-A comparative approach. Accid. Anal. Prev. 2003, 35, 991-1004.

21. Abdel-Aty, M.; Chundi, S.S.; Lee, C. Geo-spatial and log-linear analysis of pedestrian and bicyclist crashes involving school-aged children. J. Saf. Res. 2007, 38, 571-579.

22. Blazquez, C.A.; Celis, M.S. A spatial and temporal analysis of child pedestrian crashes in Santiago, Chile. Accid. Anal. Prev. 2013, 50, 304-311.

23. Wang, Y.; Kockelman, K.M. A Poisson-lognormal conditional-autoregressive model for multivariate spatial analysis of pedestrian crash counts across neighborhoods. Accid. Anal. Prev. 2013, 60, 71-84.

24. Xie, Z.; Yan, J. Detecting traffic accident clusters with network kernel density estimation and local spatial statistics: An integrated approach. J. Transp. Geogr. 2013, 31, 64-71.

25. Amin, S.R.; Zareie, A.; Amador-Jiménez, L.E. Climate change modeling and the weather-related road accidents in Canada. Transp. Res. Part D: Transp. Environ. 2014, 32, 171-183. 
26. Andrade, L.; Vissoci, J.R.N.; Rodrigues, C.G.; Finato, K.; Carvalho, E.; Pietrobon, R.; Souza, E.M.; Nihei, O.K.; Lynch, C.; Carvalho, M.D.B. Brazilian road traffic fatalities: A spatial and environmental analysis. PLoS ONE 2014, 9, 1-10.

27. Soltani, A.; Askari, S. Analysis of intra-urban traffic accidents using spatiotemporal visualization techniques. Transp. Telecommun. J. 2014, 15, 227-232.

28. Vandenbulcke, G.; Thomas, I.; Panis, L.I. Predicting cycling accident risk in Brussels: A spatial case-control approach. Accid. Anal. Prev. 2014, 62, 341- 357.

29. Yu, H.; Liu, P.; Chen, J.; Wang, H. Comparative analysis of the spatial analysis methods for hotspot identification. Accid. Anal. Prev. 2014, 66, 80-88.

30. Habibovic, A.; Davidsson, J. Causation mechanisms in car-to-vulnerable road user crashes: Implications for active safety systems. Accid. Anal. Prev. 2012, 49, 493-500.

31. Habibovic, A.; Davidsson, J. Requirements of a system to reduce car-to-vulnerable road user crashes in urban intersections. Accid. Anal. Prev. 2011, 43, 1570-1580.

32. Anderson, T.K. Kernel density estimation and K-means clustering to profile road accident hotspots. Accid. Anal. Prev. 2009, 41, 359-364.

33. Ahmed, M.M.; Abdel-Aty, M. Evaluation and spatial analysis of automated red-light running enforcement cameras. Transp. Res. Part C: Emerg. Technol. 2015, 50, 130-140.

34. Durduran, S.S. A decision making system to automatic recognize of traffic accidents on the basis of a GIS platform. Expert Syst. Appl. 2010, 37, 7729-7736.

35. Erdogan, S.; Yilmaz, I.; Baybura, T.; Gullu, M. Geographical information systems aided traffic accident analysis system case study: City of Afyonkarahisar. Accid. Anal. Prev. 2008, 40, 174-181.

36. Kingham, S.; Sabel, C.E.; Bartie, P. The impact of the "school run" on road traffic accidents: A spatio-temporal analysis. J. Transp. Geogr. 2011, 19, 705-711.

37. Steenberghen, T.; Aerts, K.; Thomas, I. Spatial clustering of events on a network. J. Transp. Geogr. 2010, 18, 411-418.

38. Xiao, J.; Liu, Y. Traffic incident detection using multiple-kernel support vector machine. J. Transp. Res. Board 2012, 2324, 44-52.

39. Xie, Z.; Yan, J. Kernel density estimation of traffic accidents in a network space. Comput. Environ. Urban Syst. 2008, 32, 396-406.

40. Yalcin, G.; Duzgun, H.S. Spatial analysis of two-wheeled vehicles traffic crashes: Osmaniye in Turkey. KSCE J. Civ. Eng. 2015, doi:10.1007/s12205-015-0661-0.

41. Brunsdon, C. Estimating probability surfaces for geographical point data: An adaptive kernel algorithm. Comput. Geosci. 1995, 21, 877-894.

42. Xie, X.; Wu, J. Some improvement on convergence rates of kernel density estimator. Appl. Math. 2014, 5, 1684-1696.

43. Silverman, B.W. Density Estimation for Statistics and Data Analysis-Monographs on Statistics and Applied Probability, 1st ed.; Chapman and Hall: London, UK, 1986; p. 200.

44. Wand, M.P.; Jones, M.C. Kernel Smoothing-Monographs on Statistics and Applied Probability, 1st ed.; Chapman and Hall: London, UK, 1995; p. 212.

45. Steenberghen, T.; Dufays, T.; Thomas, I.; Flahaut, B. Intra-urban location and clustering of road accidents using GIS: A Belgian example. Int. J. Geogr. Int. Sci. 2004, 18, 169-181. 
46. Ahmed, A.; Khan, B.A.; Khurshid, M.B.; Khan, M.B.; Waheed, A. Estimating national road crash fatalities using aggregate data. Int. J. Inj. Control Saf. Promot. 2015, doi:10.1080/17457300.2014.992352.

47. Bjørnskau, T.; Nævestad, T.-O.; Akhtar, J. Traffic safety among motorcyclists in Norway: A study of subgroups and risk factors. Accid. Anal. Prev. 2012, 49, 50-57.

48. Chiou, Y.-C.; Fu, C. Modeling crash frequency and severity using multinomial-generalized Poisson model with error components. Accid. Anal. Prev. 2013, 50, 73-82.

49. Kaplan, S.; Prato, C.G. Risk factors associated with bus accident severity in the United States: A generalized ordered logit model. J. Saf. Res. 2012, 43, 171-180.

50. Nazif-Munoz, J.I.; Quesnel-Vallée, A.; van den Berg, A. Did Chile's traffic law reform push police enforcement?-Understanding Chile's traffic fatalities and injuries reduction. Inj. Prev. 2014, doi:10.1136/injuryprev-2014-041358.

51. Nóbrega, L.M.; Cavalcante, G.M.S.; Lima, M.M.S.M.; Madruga, R.C.R.; Jorge, M.L.R.; D’avila, S. Prevalence of facial trauma and associated factors in victims of road traffic accidents. Am. J. Emerg. Med. 2014, 32, 1382-1386.

52. Philip, P.; Chaufton, C.; Orriols, L.; Lagarde, E.; Amoros, E.; Laumon, B.; Akerstedt, T.; Taillard, J.; Sagaspe, P. Complaints of poor sleep and risk of traffic accidents: A population-based case-control study. PLoS ONE 2014, 9, e114102.

53. Pirdavani, A.; Bellemans, T.; Brijs, T.; Kochan, B.; Wets, G. Assessing the road safety impacts of a teleworking policy by means of geographically weighted regression method. J. Transp. Geogr. 2014, 39, 96-110.

54. Pirdavani, A.; Bellemans, T.; Brijs, T.; Wets, G. Application of geographically weighted regression technique in spatial analysis of fatal and injury crashes. J. Transp. Eng. 2014, doi:10.1061/(ASCE)TE.1943-5436.0000680.

55. Rangel, T.; Vassallo, J.M.; Arenas, B. Effectiveness of safety-based incentives in public private partnerships: Evidence from the case of Spain. Transp. Res. Part A: Policy Pract. 2012, 46, 1166-1176.

56. Yao, S.; Loo, B.P.Y.; Lam, W.W.Y. Measures of activity-based pedestrian exposure to the risk of vehicle-pedestrian collisions: Space-time path vs. potential path tree methods. Accid. Anal. Prev. 2015, 75, 320-332.

57. Agbelie, B.R.D.K. An empirical analysis of three econometric frameworks for evaluating economic impacts of transportation infrastructure expenditures across countries. Transp. Policy 2014, 35, 304-310.

58. Qian, X.; Ukkusuri, S.V. Spatial variation of the urban taxi ridership using GPS data. Appl. Geogr. 2015, 59, 31-42.

59. Wang, Y.; Potoglou, D.; Orford, S.; Gong, Y. Bus stop, property price and land value tax: A multilevel hedonic analysis with quantile calibration. Land Use Policy 2015, 42, 381-391.

60. Chakrabortya, A.; Mishra, S. Land use and transit ridership connections: Implications for state-level planning agencies. Land Use Policy 2013, 30, 458-469.

61. Lambert, D.M.; Brown, J.P.; Florax, R.J.G.M. A two-step estimator for a spatial lag model of counts: Theory, small sample performance and an application. Reg. Sci. Urban Econ. 2010, $40,241-252$. 
62. Frondoni, R.; Mollo, B.; Capotorti, G. A landscape analysis of land cover change in the Municipality of Rome (Italy): Spatio-temporal characteristics and ecological implications of land cover transitions from 1954 to 2001. Landsc. Urban Plan. 2011, 100, 117-128.

63. Zuur, A.F.; Ieno, E.N.; Smith, G.M. Analysing Ecological Data, 26th ed.; Springer: New York, NY, USA, 2007; p. 672.

64. Zhang, L.; Gove, J.H.; Heath, L.S. Spatial residual analysis of six modeling techniques. Ecol. Model. 2005, 186, 154-177.

65. Razali, N.M.; Wah, Y.B. Power comparisons of Shapiro-Wilk, Kolmogorov-Smirnov, Lilliefors and Anderson-Darling tests. J. Stat. Model. Anal. 2011, 2, 21-33.

66. Lilliefors, H.W. On the Kolmogorov-Smirnov test for normality with mean and variance unknown. J. Am. Stat. Assoc. 1967, 62, 399-402.

67. Duncan, D.T.; Kawachi, I.; Kum, S.; Aldstadt, J.; Piras, G.; Matthews, S.A.; Arbia, G.; Castro, M.C.; White, K.; Williams, D.R. A spatially explicit approach to the study of socio-demographic inequality in the spatial distribution of trees across boston neighborhoods. Spat. Demogr. 2014, 2, 1-29.

68. Boots, B.; Tiefelsdorf, M. Global and local spatial autocorrelation in bounded regular tessellations. J. Geogr. Syst. 2000, 2, 319-348.

69. Lauridsen, J.; Kosfeld, R. A test strategy for spurious spatial regression, spatial nonstationarity, and spatial cointegration. Pap. Reg. Sci. 2006, 85, 363-377.

70. Anselin, L. Lagrange multiplier test diagnostics for spatial dependence and spatial heterogeneity. Geogr. Anal. 1988, 20, 1-17.

71. Akaike, H. Information theory and an extension of the maximum likelihood principle. In Proceedings of the Second International Symposium on Information Theory; Petrov, B., Csáki, F., Eds.; Akadémiai Kiadó: Budapest, Hungary, 1973; pp. 267-281.

72. Dirick, L.; Claeskens, G.; Baesens, B. An Akaike information criterion for multiple event mixture cure models. Eur. J. Oper. Res. 2015, 241, 449-457.

73. Symonds, M.R.E.; Moussalli, A. A brief guide to model selection, multimodel inference and model averaging in behavioural ecology using Akaike's information criterion. Behav. Ecol. Sociobiol. 2011, 65, 13-21.

74. Cheung, Y.B. Zero-inflated models for regression analysis of count data: A study of growth and development. Stat. Med. 2002, 21, 1461-1469.

75. Min, Y.; Agresti, A. Random effect models for repeated measures of zero-inflated count data. Stat. Model. 2005, 5, 1-19.

76. European Commission. Towards Low Carbon Transport in Europe-Communicating Transporet Research an Innovation; European Union, Directorate General for Mobility and Transport: Brussels, Belgium, 2012; p. 24.

77. Passafaro, P.; Rimano, A.; Piccini, M.P.; Metastasio, R.; Gambardella, V.; Gullace, G.; Lettieri, C. The bicycle and the city: Desires and emotions versus attitudes, habits and norms. J. Environ. Psychol. 2014, 38, 76-83.

78. Camilloni, L.; Farchi, S.; Chini, F.; Rossi, P.G.; Borgia, P.; Guasticchi, G. How socioeconomic status influences road traffic injuries and home injuries in Rome. Int. J. Inj. Control Saf. Promot. 2013, 20, 134-143. 
79. European Transport Safety Council (ETSC). A Challenging Start towards the E.U. 2020 Road Safety Target; 6th Road Safety PIN Report; ETSC: Brussels, Belgium, 2012; p. 96.

80. Gorios, C.; Souza, R.M.; Gerolla, V.; Maso, B.; Rodrigues, C.L.; Armond, J.E. Acidentes de transporte de crianças e adolescentes em serviço de emergência de hospital de ensino, Zona Sul da cidade de São Paulo. Rev. Bras. Ortop. 2014, 49, 391-395.

81. Vasconcellos, E.A. Reassessing traffic accidents in developing countries. Transp. Policy 1995, 2, 263-269.

82. Vasconcellos, E.A. Urban development and traffic accidents in Brazil. Accid. Anal. Prev. 1999, 31, 319-328.

83. Bassani, M.; Dalmazzo, D.; Marinelli, G.; Cirillo, C. The effects of road geometrics and traffic regulations on driver-preferred speeds in northern Italy. An exploratory analysis. Transp. Res. Part F: Traffic Psychol. Behav. 2014, 25, 10-26.

84. Wegman, F.; Zhang, F.; Dijkstra, A. How to make more cycling good for road safety? Accid. Anal. Prev. 2012, 44, 19-29.

85. Ghafghazi, G.; Hatzopoulou, M. Simulating the environmental effects of isolated and area-wide traffic calming schemes using traffic simulation and microscopic emission modeling. Transportation 2014, 41, 633-649.

86. Ariën, C.; Brijs, K.; Brijs, T.; Ceulemans, W.; Vanroelen, G.; Jongen, E.M.M.; Daniels, S.; Wets, G. Does the effect of traffic calming measures endure over time? - A simulator study on the influence of gates. Transp. Res. Part F: Traffic Psychol. Behav. 2014, 22, 63-75.

87. Alemany, R.; Ayuso, M.; Guillén, M. Impact of road traffic injuries on disability rates and long-term care costs in Spain. Accid. Anal. Prev. 2013, 60, 95-102.

88. Salvarani, C.P.; Colli, B.O.; Carlotti Júnior, C.G. Impact of a program for the prevention of traffic accidents in a southern Brazilian city: A model for implementation in a developing country. Surg. Neurol. 2009, 72, 6-14.

(C) 2015 by the authors; licensee MDPI, Basel, Switzerland. This article is an open access article distributed under the terms and conditions of the Creative Commons Attribution license (http://creativecommons.org/licenses/by/4.0/). 